\title{
FORMULATION AND EVALUATION OF LYCOPENE LOADED COLLOIDAL MICROPARTICLES
} GEL

\section{MONISHA BANSAL*, MANPREET KAUR WALIA, GURFATEH SINGH, S. L. HARIKUMAR}

University School of Pharmaceutical Sciences, Rayat Bahra University, Saharuan, Mohali, Punjab, 140104 India, *Shaheed Udham Singh College of Pharmacy, Tangori, Mohali

Email: monishabansal595@gmail.com

Received: 29 Jul 2019, Revised and Accepted: 02 Sep 2019

ABSTRACT

Objective: The objective of the present investigation was to design and evaluate a gel containing lycopene loaded colloidal microparticles.

Methods: The lycopene loaded colloidal microparticles were successfully prepared by Cloud point technique to form colloids using Tween 40 and Tween 60 surfactant solution and then incorporated into microparticles by solvent evaporation method using polymer like HPMC and ethyl cellulose. These colloidal microparticles were evaluated for particle size (PS), drug loading (DL), entrapment efficiency (EE), Scanning Electron Microscopy (SEM). Further, these colloidal microparticles were incorporated into a topical formulation i.e., gel. This topical formulation was then evaluated for macroscopic examination, viscosity, drug content, spreadability, antioxidant activity, in vitro permeation and release kinetics.

Results: Colloidal microparticles were successfully prepared and the particle size, drug loading and entrapment efficiency were found to be $249.45 \pm 14.2 \mu \mathrm{m}, 49.8 \pm 0.96 \%$ and $93.4 \pm 0.26 \%$ respectively. FTIR study depicted no chemical interaction between pure drug lycopene and other excipients. The topical formulation showed sustained release and followed Korsmeyer-Peppas release kinetics model.

Conclusion: The sustained release topical formulation of lycopene was successfully prepared using Tween 40 and Tween 60 surfactant solution and combination of HPMC and ethyl cellulose and evaluated for several parameters.

Keywords: Lycopene, Sustained release, HPMC, Tween 40 and 60, Colloidal Microparticles

(C) 2019 The Authors. Published by Innovare Academic Sciences Pvt Ltd. This is an open access article under the CC BY license (http://creativecommons.org/licenses/by/4.0/) DOI: http://dx.doi.org/10.22159/ijap.2019v11i6.35130

\section{INTRODUCTION}

Lycopene is a powerful antioxidant which can prevent human skin against UVR-induced effects [1]. Lycopene helps in providing protection against acute and potentially longer-term aspects of photo damage [2]. Lycopene in its original form is a lyophilic drug [3]. Lycopene-based product had a much greater protective ability from photodamage than the product containing the mixture of vitamins and lycopene has suitable characteristics to be used successfully in the prevention of cutaneous damage by free radicals [4]. The antioxidant ability of lycopene was probably due to its high reductive power. It act as a preventative agent via inhibition of epidermal ornithine decarboxylase activity, reducing inflammatory responses, maintaining normal cell proliferation and possibly preventing DNA damage as indicated by blocking the necessitating step of apoptosis following UVB injury [5]. It has poor aqueous solubility and this reduces the flexibility of drug formulation and administration [6].

Microparticle entrapped micelles is a delivery system in which the particles of the micellar range are ensemble for drug and gene delivery in specific parts of the body. Microparticles containing micelles have the potential for delivering micelle encapsulated hydrophobic drug on targeted site [7-11]. Micelles have been used as drug carriers for administration and exhibit many advantages including their ease of production, long circulation times and having surfaces that are readily modified with targeting ligands. Drug loaded colloidal microparticles can sustain the release of drug and provide patient compliance by ease of application through topical drug delivery system. The lower solubility of lycopene in aqueous solvents makes it a selective candidate for the improvement of solubility and delivering the drug by formulating colloidal microparticles [12].

In the present investigation, sustained release topical formulation of lycopene loaded colloidal microparticles was prepared. Colloids were prepared by Cloud point technique using Tween 40 and Tween 60 surfactant solution and then incorporated into microparticles by solvent evaporation method using polymer like HPMC and ethyl cellulose. The formulated colloidal microparticles were also evaluated for different parameters such as Percentage yield, Particle Size, Entrapment efficiency, FTIR study and SEM. The optimised colloidal microparticles were incorporated into gel and evaluated for macroscopic examination, viscosity, drug content, spreadability, antioxidant activity, in vitro permeation and release kinetics.

\section{MATERIALS AND METHODS}

\section{Materials}

Lycopene was obtained as a gift sample from Ion Healthcare (P) Ltd, Baddi. Other materials mainly Methanol, Chloroform, hexane, Petroleum ether, Tween 40 and Tween 60 used were of analytical grades and procured commercially.

\section{Formulation of drug loaded colloids}

Drug loaded colloids were formulated by Cloud Point Technique. The cloud point temperature (CPT) were obtained by placing the test tubes each containing a surfactant solution of $1 \%$ ( $1 \mathrm{ml}$ in $100 \mathrm{ml}$ ), $5 \%, 10 \%, 15 \%$ and $25 \%(\mathrm{v} / \mathrm{v})$ of Tween 60 , Tween 40 and mixture of Tween 40 and Tween 60 into a temperature-controlled bath. The sample solutions were heated to a temperature where cloudy appearance was visualized. The temperature at the first sign of the turbidness was taken as the CPT [13].

\section{Micellar solubilization}

Micellar solubilization of lycopene was performed by employing cloud point technique, wherein drug was solubilized in surfactant solution at CPT. Aqueous surfactant solutions of $1 \%, 5 \%, 15 \%$ and $25 \%(\mathrm{v} / \mathrm{v})$ of Tween 60 , Tween 40 and mixture of Tween 40 and Tween 60 were used as solubilizing media. The surfactant solutions $(5 \mathrm{ml})$ were taken in centrifuge tubes, heated in a water bath up to CPT and excess amount of lycopene was added under stirring, solutions were cooled to room temperature (RT) and the solubility of lycopene was estimated. These lots were kept under shaking at RT using orbital shaker for $24 \mathrm{~h}$ to attain equilibrium. The aliquots of these samples were centrifuged, filtered through a $0.45 \mathrm{~mm}$ nylon membrane filter, suitably diluted with n-hexane and were subjected to UV spectrophotometric analysis of lycopene at $517 \mathrm{~nm}$. 


\section{Formulation of colloidal microparticles}

Microparticles formulations using combination of hydroxypropyl methyl cellulose (HPMC) and ethyl cellulose as a carrier polymer were prepared using solvent evaporation technique. Desired quantity of HPMC and ethyl cellulose polymer was dissolved in 8.5 $\mathrm{ml}$ of acetone and dispersed by using a magnetic stirrer. The micellar solution of lycopene was added to the polymer solution and mixed for $15 \mathrm{~min}$, followed by magnesium stearate $(100 \mathrm{mg})$ and then mixed thoroughly. The resulting dispersion was added in a thin stream to a mixture of $90 \mathrm{ml}$ light liquid paraffin contained in a 250 $\mathrm{ml}$ beaker, while stirring at $700 \mathrm{rpm}$ using a mechanical stirrer.

Stirring was continued for $3 \mathrm{~h}$ until the acetone evaporated completely. The microparticles formed were filtered using filter paper. The residue was washed 4-5 times with $50 \mathrm{ml}$ portions of $\mathrm{n}$ hexane. The product was then dried at room temperature for $24 \mathrm{~h}$ [14-17]. The composition is given in table 1 .

Table 1: Composition of various formulations of colloidal microparticles

\begin{tabular}{|c|c|c|c|c|c|c|c|c|c|}
\hline \multirow[t]{2}{*}{ Ingredients (mg/ml) } & \multicolumn{9}{|c|}{ Formulations } \\
\hline & M1 & M2 & M3 & M4 & M5 & M6 & M7 & M8 & M9 \\
\hline Ethyl cellulose & 10 & 15 & 20 & 10 & 15 & 20 & 10 & 15 & 20 \\
\hline HPMC & 5 & 10 & 20 & 5 & 10 & 20 & 5 & 10 & 20 \\
\hline Micellar solution (ml) & 5.1 & 5.1 & 5.1 & 3.6 & 3.6 & 3.6 & 4.1 & 4.1 & 4.1 \\
\hline
\end{tabular}

\section{Drug-loading efficiency and encapsulation efficiency}

The amount of lycopene encapsulated in the microparticles was measured by an ultraviolet detector at the $\lambda \max$ value of $507 \mathrm{~nm}$. The colloidal microparticles were suitably diluted with n-hexane and filtered before determination. Encapsulation efficiency (EE \%) and drug loading (DL \%) was calculated with the following equations $[18,19]$ :

$$
\begin{gathered}
\mathrm{EE} \%=\frac{\text { Actual amount of drug encapsulated in microparticles }}{\text { initial amount of drug used in microparticles }} * 100 \\
\mathrm{DL} \%=\frac{\text { Weight of drug in microparticles }}{\text { Weight of particles }} * 100
\end{gathered}
$$

Actual amount of drug encapsulated in microparticles is calculated by: $A=\varepsilon c l$

\section{Particle size analysis}

A thin film of microparticles was spread on a slide and covered with cover slip. The slide was observed under optical microscope [17].

\section{Yield of colloidal microparticles}

The Yield of colloidal microparticles was calculated by given formulae $[20,21]$.

$$
\% \text { yield }=\frac{\text { Actual weight of product }}{\text { Total weight of excipients and drugs }} * 100
$$

\section{Fourier-transform infrared spectroscopy}

FTIR spectrum of pure lycopene and lycopene and tween 60 were observed on FTIR spectrophotometer. FTIR spectroscopy was carried out for investigating any kind of chemical interactions among pure lycopene and other excipients in formulation [22, 23].

\section{Scanning electron microscope (SEM)}

The morphology of prepared Colloidal microparticles was observed using a Scanning Electron Microscope (SEM) [24].

\section{Formulation of colloidal microparticles incorporated gel}

The weighed amount of Carbopol 934 LR powder was slowly dispersed in $50 \%$ distilled water with vigorous stirring, so as to avoid the clump formation and air entrapment. After complete dispersion, the gel solution was kept in dark for $24 \mathrm{~h}$ for complete swelling of Carbopol. Accurately weighed amount of Lycopene colloidal microparticles were then incorporated in Carbopol gel with continuous stirring. In another beaker other ingredients were dissolved in remaining $25 \%$ distilled water with moderate heating and stirring. The above solution was added slowly into the Carbopol gel containing lycopene with continuous stirring using magnetic stirrer. Care has been taken during preparation to avoid entrapment of air bubbles in a gel. Finally formed gel was then neutralized by sufficient quantity of sodium hydroxide solution $(1 \% \mathrm{w} / \mathrm{v})$. Final volume of formulation was adjusted by remaining amount of

\begin{tabular}{|c|c|c|c|c|c|c|c|}
\hline \multirow[t]{2}{*}{ S. No. } & \multirow[t]{2}{*}{ Ingredients } & \multicolumn{6}{|c|}{ Quantities (\% w/w) } \\
\hline & & G1 & G2 & G3 & G4 & G5 & G6 \\
\hline 1 & Colloidal Microparticles & 1.5 & 1.5 & 1.5 & 1.5 & 1.5 & 1.5 \\
\hline 2 & Carbopol 934 & 0.5 & 1 & 1.5 & - & - & - \\
\hline 3 & HPMC & - & - & - & 3 & 3.5 & 4 \\
\hline 4 & Glycerin & 5 & 5 & 5 & 5 & 5 & 5 \\
\hline 5 & Triethanolamine & 2 & 2 & 2 & 2 & 2 & 2 \\
\hline 6 & Methyl paraben & 0.20 & 0.20 & 0.20 & 0.20 & 0.20 & 0.20 \\
\hline 7 & Propyl paraben & 0.05 & 0.05 & 0.05 & 0.05 & 0.05 & 0.05 \\
\hline 8 & Sodium hydroxide & q.s. & q.s. & q.s. & q.s. & q.s. & $q . s$. \\
\hline 9 & Distilled water & q.s. & q.s. & q.s. & q. $s$. & q.s. & q. $s$. \\
\hline
\end{tabular}
distilled water [25-28].

Table 2: Composition of various formulations of colloidal microparticles loaded gel

\section{Macroscopic examination}

The physical appearance of the prepared formulation were checked and compared visually for their colour, homogeneity, consistency [29].

\section{Determination of $\mathrm{pH}$}

The $\mathrm{pH}$ values of gel formulations were determined by using digital pH meter [30,31].

\section{Determination of viscosity}

Brookfield digital viscometer was used to measure the viscosity (in cps) of the prepared gel formulation [32].

\section{Determination of drug content}

$1 \mathrm{~g}$ formulation was taken in a $50 \mathrm{ml}$ volumetric flask and made up to volume with hexane and shaken well to dissolve the active constituents in hexane. The solution was filtered through Whatman filter paper and $0.1 \mathrm{ml}$ of the filtrate was pipetted out and diluted to $10 \mathrm{ml}$ with hexane. The content of active constituents was estimated spectrophotometrically by using standard curve plotted at $470.8 \mathrm{~nm}$ [33].

\section{Determination of spreadability}

Spreading coefficient was determined by apparatus which consisted of a wooden block that was attached to a pulley at one end. 
Spreading coefficient was measured on the basis of 'Slip' and 'Drag' characteristics of gels.

\section{Determination of antioxidant activity of formulated gel}

$1 \mathrm{gm}$ of sample was taken and $0.67 \%$ of aqueous thiobarbituric acid $(2 \mathrm{ml})$ and benzene $(2.5 \mathrm{ml})$ were added. This mixture was shaken continuously for $1 \mathrm{~h}$ using mechanical shaker. After $1 \mathrm{~h}$ supernatant was taken and placed in boiling water bath for $1 \mathrm{~h}$. After cooling, absorbance of supernatant was measured at $540 \mathrm{~nm}$ using UV visible spectrophotometer. The TBA value was expressed as mg. malondialdehyde/kg sample using the following equation:

$$
\mathrm{TBA}=7.8 \times 0 . \mathrm{D} .
$$

Where, 0 . D. is the absorbance at $540 \mathrm{~nm}$.

\section{In vitro permeation test}

The in vitro permeation tests were performed using Franz diffusion cell. The diffusional area of the cell is $1.75 \mathrm{~cm}^{2}$ and the receptor compartment had a capacity of approximately $10.5 \mathrm{ml}$. The membrane was cut to a diameter of $25 \mathrm{~mm}$ and saturated for $30 \mathrm{~min}$ in receptor medium (phosphate buffer $\mathrm{pH}$ 7.4) before starting the experiment. The cell was filled with degassed receptor medium and the membrane was placed in the top of the receptor compartment and checked for air bubbles. An aliquot of the sample was measured with the aid of a syringe and then placed in the cavity of a dosage wafer (donor compartment), on top of the membrane. The amount applied was around $50 \mathrm{mg}$ of gel. With a spatula, the gel was spread uniformly filling the donor compartment. A glass disk was carefully placed on the sample to occlude it, and an aligner cap was then used to centralize the assembly, which was held together by a clamp. The receptor medium was maintained at $37 \pm 2{ }^{\circ} \mathrm{C}$ under constant stirring. To characterize the drug release, $1 \mathrm{ml}$ samples were collected after 1, 2, 3, 4, 5, 6 and $7 \mathrm{~h}$. After sampling, the volume collected is replaced with fresh receptor medium. The amount of lycopene is assayed by UV analysis [34].

\section{RESULTS AND DISCUSSION}

\section{Micellar solubilization}

The surfactant solutions $(5 \mathrm{ml})$ were taken in centrifuge tubes, heated in a water bath up to CPT and excess amount of lycopene was added under stirring, solutions were cooled to room temperature (RT) and the solubility of lycopene was estimated by UV Spectroscopy and results are tabulated in table 3.

Table 3: Solubility of lycopene in various surfactant solutions

\begin{tabular}{lllll}
\hline S. No. & Concentration (\% v/v) & \multicolumn{2}{l}{ Solubility of lycopene (mg/ml) } \\
\cline { 3 - 5 } & & Tween 40 & Tween 60 & Mixture of Tween 40 and 60 \\
\hline 1 & 1 & 3.404 & 5.7 & 5.217 \\
2 & 5 & 14.465 & 19.8 & 17.2 \\
3 & 10 & 38.76 & 53.9 & 47.4 \\
4 & 15 & 58.656 & 82.3 & 72.84 \\
\hline
\end{tabular}

\section{Evaluation of colloidal microparticles}

The yield, particle size, drug loading and entrapment efficiency increases with increase in polymer concentration. From the results, it was observed that the drug is uniformly distributed within the polymer matrix. These findings were found to be consistent with other studies [25]. The particle size increases with the increase in the polymer concentration in the microparticles. This was due to increase in relative viscosity, which led to increase in particle size. A higher concentration of polymer produces more viscous dispersion, which formed larger droplets and consequently larger microparticles [26, 27]. These results are depicted in table 4.

Table 4: Evaluation of colloidal microparticles

\begin{tabular}{lllll}
\hline Formulation code & \% yield & Particle size $(\boldsymbol{\mu m})$ & Drug loading (\%) & Entrapment efficiency (\%) \\
\hline M1 & 87.94 & 222.1 & $45.92 \pm 0.28$ & $70.99 \pm 0.54$ \\
M2 & 90.51 & 256.5 & $41.97 \pm 1.16$ & $77.56 \pm 1.22$ \\
M3 & 96.4 & 378.6 & $35.64 \pm 1.28$ & $84.75 \pm 1.08$ \\
M4 & 83.45 & 235.6 & $53.78 \pm 0.83$ & $78.9 \pm 1.12$ \\
M5 & 91.78 & 249.4 & $49.8 \pm 0.96$ & $93.4 \pm 0.26$ \\
M6 & 95.7 & 362.5 & $38.04 \pm 0.88$ & $89.8 \pm 0.41$ \\
M7 & 85.42 & 228.7 & $50.32 \pm 1.22$ & $75.58 \pm 1.52$ \\
M8 & 90.38 & 263.4 & $43.54 \pm 0.47$ & $80.34 \pm 0.77$ \\
M9 & 97.4 & 381.7 & $35.41 \pm 1.54$ & $85.07 \pm 0.94$ \\
\hline
\end{tabular}

mean \pm SD, $n=3$

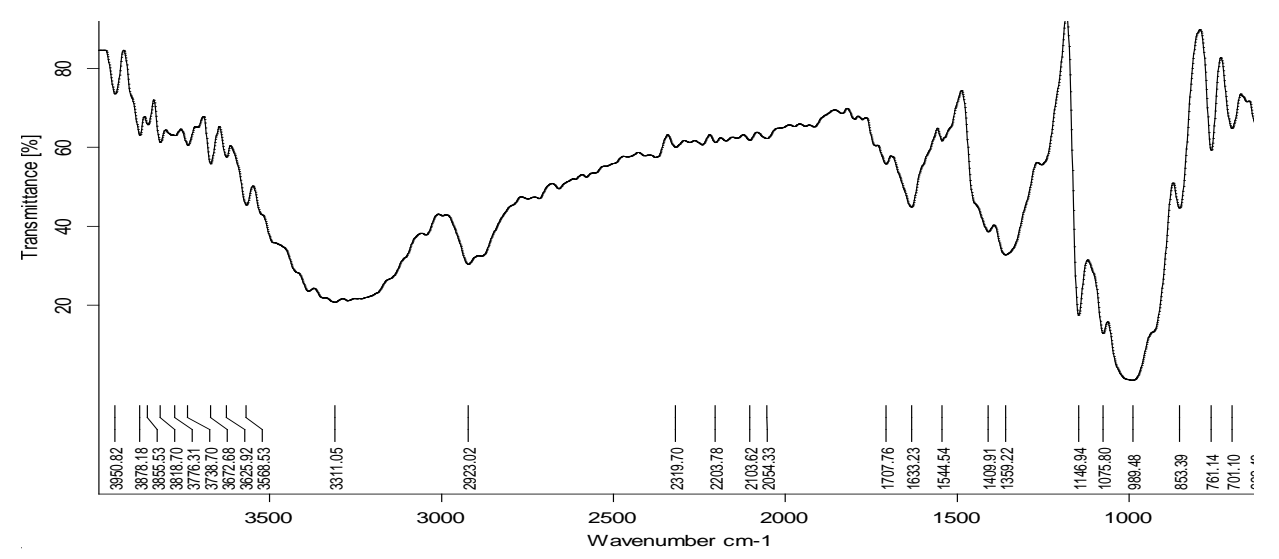

Fig. 1: FTIR spectra of Lycopene drug 


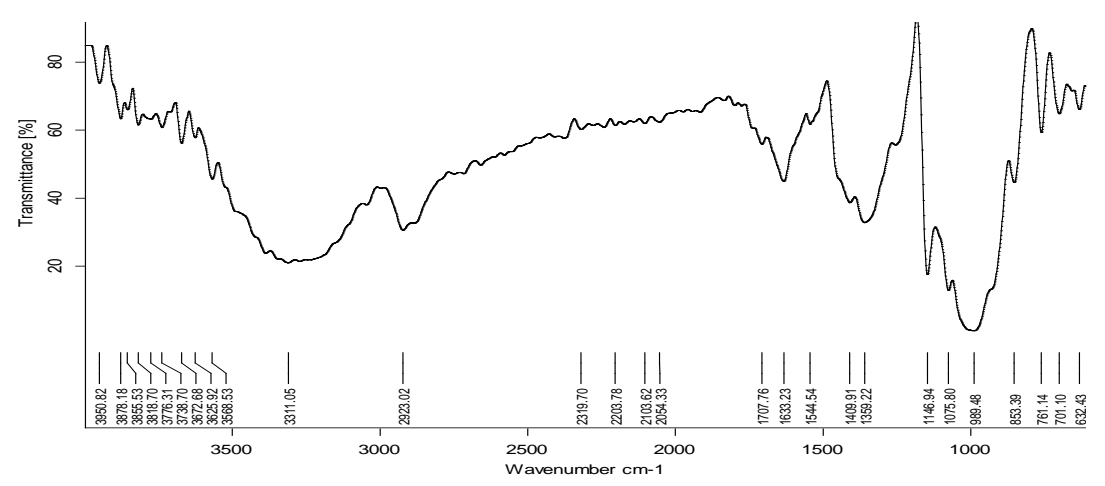

Fig. 2: FTIR spectra of lycopene and tween 60

\section{Fourier-transform infrared spectroscopy}

The FTIR spectra of lycopene exhibited principle peaks at wave numbers 632.43, 701.10, 761.14, 853.39, 989.48, 1075.80, $1146.94,1359.22,1633.23,2923.02$ and $3311.05 \mathrm{~cm}^{-1}$ indicating the conformation of lycopene. In the FTIR spectra of physical mixture of drug with excipients, the principle peaks of drug were present at the above numbers. So, from the spectrum, it can be concluded that there was no interaction between drug and excipients used in the formulation. The FTIR spectrum of pure lycopene and lycopene and tween 60 are shown in fig. 1 and fig. 2.

After considering the particle size and entrapment efficiency as optimization parameters the formulation M5 was considered as the best formulation having maximum entrapment efficiency and optimum particle size.

\section{Surface morphology}

Surface morphology of colloidal microparticles of formulation M5 was investigated with the Scanning electron microscope. SEM photomicrograph is shown in fig. 3. The particle surface was found to be slightly wrinkled, irregularly shaped and discrete. The smoothness of the surface may increase with the increasing concentration of polymer. Very less particulate matter of the drug were seen on the surface of the microparticles indicating uniform distribution of the drug in the polymer network. The roughness of the microparticles can be due to washing out of the surfactant solution and also due to solvent evaporation [27, 28].

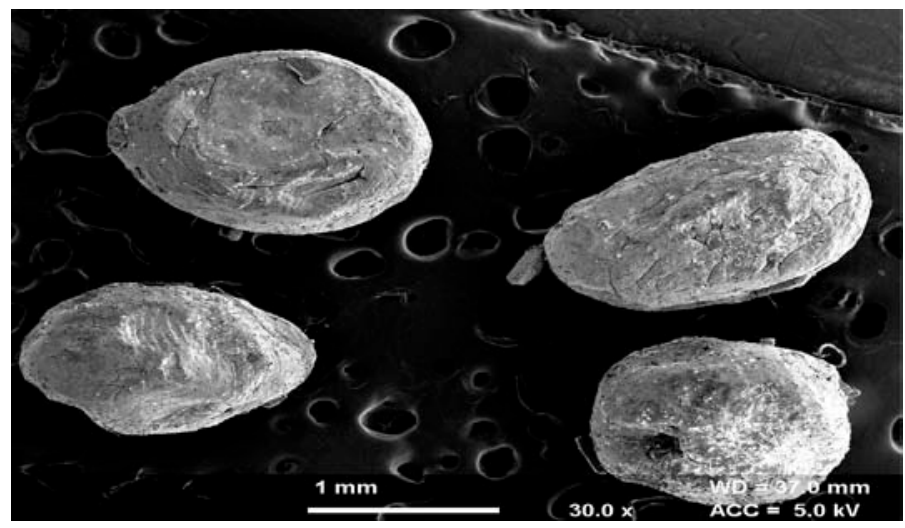

Fig. 3: Scanning electron photomicrographs of colloidal microparticles

\section{Evaluation of gel}

The gel containing colloidal microparticles formulations were clear and transparent with a smooth and homogeneous appearance with carbopol and white viscous with HPMC. The $\mathrm{pH}$ values of all prepared formulation of gel containing colloidal microparticles ranged from 5.8 to 6.8. The $\mathrm{pH}$ of the formulations was considered within acceptable $\mathrm{pH}$ range (5.5-6.5) and $\mathrm{pH}$ measurement was essential to ensure non-irritating nature of the formulation $[39,40]$. The viscosity of gel increased with increase in polymer concentration. The spreadability decreased with increased polymer concentration. Lesser the time taken for separation of two slides, better the spreadability [41]. Drug content was calculated using the equation, which was obtained by linear regression analysis of calibration curve. The drug content was observed in the range of 91.62 to $95.48 \%$. The macroscopic examination, $\mathrm{pH}$, viscosity, spreadability and drug content are represented in table 5 .

Table 5: Evaluation of colloidal microparticles loaded gel

\begin{tabular}{|c|c|c|c|c|c|c|}
\hline \multirow[t]{2}{*}{ Parameters } & \multicolumn{6}{|c|}{ Formulation code } \\
\hline & G1 & G2 & G3 & G4 & G5 & G6 \\
\hline Appearance & Clear & Clear & Clear & White viscous & White viscous & White viscous \\
\hline $\mathrm{pH}$ & 5.8 & 6.1 & 6.8 & 5.5 & 6.0 & 6.4 \\
\hline Viscosity (cps) & 505 & 717 & 923 & 381 & 535 & 721 \\
\hline Drug Content (\%) & $91.6 \pm 0.02$ & $95.4 \pm 0.05$ & $92.3 \pm 0.03$ & $89.8 \pm 0.07$ & $93.4 \pm 0.8$ & $91.8 \pm 0.9$ \\
\hline Spreadability & 13.6 & 10 & 8.82 & 15.7 & 12.8 & 10.2 \\
\hline Antioxidant value & 1.7 & 2.69 & 1.73 & 1.4 & 1.7 & 1.6 \\
\hline
\end{tabular}

$($ mean $\pm S D, n=3)$ 


\section{In vitro permeation test}

The in vitro permeation tests were performed using Franz diffusion cell. The cumulative percentage drug release from gel loaded with colloidal microparticles showed that the cumulative drug release from gel was in descending order i.e.,
$\mathrm{G} 1>\mathrm{G} 2>\mathrm{G} 4>\mathrm{G} 5>\mathrm{G} 3>\mathrm{G} 6$. The amount of drug release or permeation through the cellophane membrane was showed to be based on viscosity or concentration of gelling agent. The drug release was found to decrease with increase in Carbopol concentration. In vitro release data of lycopene from gel loaded with colloidal microparticles is tabulated in table 6 .

Table 6: \% cumulative drug release

\begin{tabular}{|c|c|c|c|c|c|c|}
\hline \multirow[t]{2}{*}{ Time (h) } & \multicolumn{6}{|c|}{$\%$ cumulative drug release } \\
\hline & G1 & G2 & G3 & G4 & G5 & G6 \\
\hline 1 & $7.4 \pm 0.67$ & $5.4 \pm 0.90$ & $4.2 \pm 1.4$ & $6.6 \pm 0.08$ & $5 \pm 0.08$ & $3.8 \pm 1.7$ \\
\hline 2 & $12.4 \pm 0.35$ & $11.8 \pm 0.46$ & $9.7 \pm 0.6$ & $11.1 \pm 0.5$ & $9.86 \pm 1.2$ & $8.9 \pm 1.1$ \\
\hline 3 & $16.3 \pm 1.45$ & $16.0 \pm 0.33$ & $14.2 \pm 0.7$ & $14.9 \pm 0.4$ & $14.6 \pm 0.5$ & $12.1 \pm 0.4$ \\
\hline 4 & $23.9 \pm 0.89$ & $20.2 \pm 0.74$ & $17.4 \pm 0.2$ & $22.1 \pm 0.7$ & $18.3 \pm 0.8$ & $15.5 \pm 0.07$ \\
\hline 5 & $34.1 \pm 0.57$ & $27.3 \pm 1.25$ & $24.7 \pm 0.5$ & $30.2 \pm 0.09$ & $25.2 \pm 0.96$ & $21.9 \pm 0.2$ \\
\hline 6 & $43.6 \pm 0.45$ & $39.7 \pm 0.82$ & $31.0 \pm 1.2$ & $36.5 \pm 0.1$ & $32.05 \pm 0.4$ & $27.2 \pm 0.08$ \\
\hline 7 & $66.6 \pm 1.21$ & $60.9 \pm 0.75$ & $42.8 \pm 1.8$ & $57.8 \pm 0.67$ & $43.9 \pm 0.09$ & $37.5 \pm 0.9$ \\
\hline
\end{tabular}

mean $\pm \mathrm{SD}, \mathrm{n}=3$

Table 7: In vitro drug release profile

\begin{tabular}{|c|c|c|c|c|c|c|}
\hline \multirow[t]{3}{*}{ Model name } & \multicolumn{6}{|c|}{ Formulation code } \\
\hline & G1 & G2 & G3 & G4 & G5 & G6 \\
\hline & $\mathbf{r}^{2}$ & $\mathbf{r}^{2}$ & $\mathbf{r}^{2}$ & $\mathbf{r}^{2}$ & $\mathbf{r}^{2}$ & $\mathbf{r}^{2}$ \\
\hline Zero order model & 0.9588 & 0.948 & 0.981 & 0.958 & 0.982 & 0.981 \\
\hline First order model & 0.908 & 0.902 & 0.964 & 0.915 & 0.96 & 0.968 \\
\hline Higuchi model & 0.919 & 0.908 & 0.954 & 0.921 & 0.954 & 0.955 \\
\hline Korsmeyer-Peppas model & 0.973 & 0.979 & 0.993 & 0.977 & 0.993 & 0.993 \\
\hline
\end{tabular}

\section{Determination of release kinetics}

The mathematical models were used to evaluate the kinetics and mechanism of drug release. The model that gave high correlation coefficient $(r)$ value was considered as the best fit of the release data [42]. The in vitro drug release profiles of various models are tabulated in table 7.
A graphical representation of the log cumulative percentage drug release vs. log time originated as a straight line shown in fig. 4. The release mechanism deviates from the Fickian diffusion following an anomalous diffusion or non-fickian diffusion, which referred to the combination of both diffusion and erosion controlled rate release.

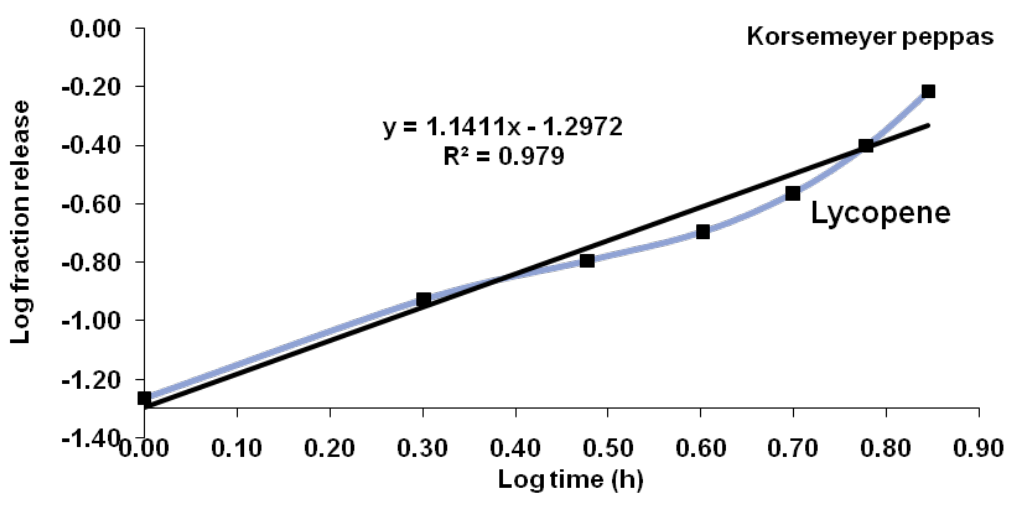

Fig. 4: Korsmeyer-peppas graph

Table 7 revealed that the Korsmeyer-Peppas equation was followed for the in vitro diffusion of gel containing colloidal microparticles. The Korsmeyer-Peppas equation gave the value of $n$ which is 5.6 i.e. higher than 0.45 . The diffusion coefficient of Korsmeyer-Peppas equation showed that the Non-Fickian mechanism was basically involved in the drug release from gel containing colloidal microparticles.

\section{CONCLUSION}

In a nutshell to conclude, colloidal microparticles system is a vital tool in improving the solubility of lipophilic drug. The current studies resulted in the successful development of sustained release gel containing colloidal microparticles of lycopene. The lycopene's lipophilic nature was masked by formulating micelles using Tween 40 and Tween 60 . These colloids were then converted into solid product by forming microparticles. These colloidal microparticles were incorporated into topical formulation which showed sustained release and grossly improve the patient compliance. The formulation could be a successful approach to prevent human skin against UVR-induced effects.

\section{ACKNOWLEDGEMENT}

We wish to express our gratefulness to Sr. Gurvinder Singh Bahra (Honorable Chancellor), Dr. Daljit Singh (Honorable Vice Chancellor) of Rayat-Bahra University Mohali for their praiseworthy inspiration, beautiful research platform, environment and regular support for the completion of this research proposal. 


\section{AUTHORS CONTRIBUTIONS}

All the author have contributed equally

\section{CONFLICT OF INTERESTS}

\section{Declared none}

\section{REFERENCES}

1. Evans JA, Johnson EJ. The role of phytonutrients in skin health. Nutr 2010;2:903-28.

2. Rizwan M, Rodriguez Blanco I, Harbottle A, Birch Machin MA, Watson RE, Rhodes LE. Tomato paste rich in lycopene protects against cutaneous photodamage in humans in vivo: a randomized controlled trial. Br J Dermatol 2011;164:154-62.

3. Mozos I, Stoian D, Caraba A, Malainer C, Horbańczuk JO, Atanasov AG. Lycopene and vascular health. Front Pharmacol 2018;9:521.

4. Andreassi M, Stanghellini E, Ettorre A, Di Stefano A, Andreassi L. Antioxidant activity of topically applied lycopene. J Eur Acad Dermatol Venereol 2004;18:52-5.

5. Fazekas Z, Gao D, Saladi R, Lu Y, Lebwohl M, Wei H. Protective effects of lycopene against ultraviolet b-induced photodamage. Nutr Cancer 2003;47:181-7.

6. Savjani KT, Gajjar AK, Savjani JK. Drug solubility: importance and enhancement techniques. ISRN Pharm; 2012. p. 1-10.

7. Okano T. Block copolymer design for camptothecin incorporation into polymeric micelles for passive tumor targeting. Pharm Res 2004;21:2001-8.

8. Cai S, Vijayan K, Cheng D, Lima EM, Discher DE. Micelles of different morphologies-advantages of worm-like filomicelles of PEO-PCL in paclitaxel delivery. Pharm Res 2007;24:2099-109.

9. Hofman JW, Carstens MG, Van Zeeland F, Helwig C, Flesch FM, Hennink WE. Photocytotoxicity of mTHPC (temoporfin) loaded polymeric micelles mediated by lipase catalyzed degradation. Pharm Res 2008;25:2065-73.

10. Vakil R, Knilans K, Andes D, Kwon GS. Combination antifungal therapy involving amphotericin $\mathrm{B}$, rapamycin and 5 fluorocytosine using PEG-phospholipid micelles. Pharm Res 2008;25:2056-64.

11. Yang Y, Chen C, Yang J, Tsai T. Spray-dried microparticles containing polymeric micelles encapsulating hematoporphyrin. AAPS J 2010;12:138-46.

12. Bansal M, Jamil S. Micellar microparticles: a novel approach to topical drug delivery system. Int J Appl Pharm 2018;10:1-5.

13. Taş D, Çete S. Micellar properties and antimicrobial activity of a mixed surfactant system constituted by sodium dodecyl sulfate and cetylpyridinium chloride. Indian $\mathrm{J}$ Pharm Educ 2017;51:580-7.

14. Sudhamani T, Reddy K, Kumar V, Ramadoss R, Ganesan V. Preparation and evaluation of ethyl cellulose microspheres of ibuprofen for sustained drug delivery. Int J Pharm Res Dev 2010;2:1-5.

15. Ganesan P, Soundararajan R, Shanmugam U, Ramu V. Development, characterization and solubility enhancement of comparative dissolution study of second generation of solid dispersions and microspheres for poorly water soluble drug. Asian J Pharm Sci 2015;10:433-41.

16. Nagendra R, Charan C, Joshi K, Jayanthi C. Preparation and evaluation of microparticles containing oxybutynin chloride for controlled release. Asian J Biomed Pharm Sci 2015;5:15-7.

17. Rai S, Ravikumar P. Development and evaluation of microsphere based topical formulation using design of experiments. Int J Pharm Sci 2016;78:182-92.

18. Kandav G, Bhatt D, Jindal D. Formulation and evaluation of allopurinol loaded chitosan nanoparticles. Int J Appl Pharm 2019;11:49-52.

19. Patel BK, Parikh RH, Aboti PS. Development of oral sustained release rifampicin loaded chitosan nanoparticles by design of an experiment. J Drug Delivery 2013;1-10. http://dx.doi.org/10.1155/2013/370938
20. Najmuddin M, Ahmed A, Shelar S, Patel V, Khan T. Floating microspheres of ketoprofen: formulation and evaluation. Int J Pharm Pharm Sci 2010;2:164-8.

21. Ararath D, Velmurugan S. Formulation and evaluation of nevirapine mucoadhesive microspheres. Int J Pharm Pharm Sci 2015;7:342-8.

22. Deshmukh M, Mohite S. Formulation and characterization of olanzepine loaded mucoadhesive microspheres. Asian J Pharm Clin Res 2017;10:249-55.

23. Girotra P, Singh SK. A comparative study of orally delivered PBCA and ApoE coupled BSA nanoparticles for brain targeting of sumatriptan succinate in the therapeutic management of migraine. Pharm Res 2016;33:1682-95.

24. Venkatesh D, Karki R, Jha S, Lakshmi A, Kumar G, Goli D. Formulation and evaluation of microspheres containing fluvastatin sodium. Int J Drug Dev Res 2012;4:306-14.

25. Chowdary K, Kumar PA. Formulation and evaluation of topical drug delivery systems of ciprofloxacin. Ind J Pharm Sci 1996;58:47-50.

26. Mura P, Faucci MT, Bramanti G, Corti P. Evaluation of transcutol as a clonazepam transdermal penetration enhancer from hydrophilic gel formulations. Eur J Pharm Sci 2002;9:365-72.

27. Patel S, Changediya B, Gadhave MV, Jadhav S, Gaikwad DD. Formulation and evaluation of diclofenac sodium gel by using carbopol. Int Res J Sci Eng 2018;3:65-8.

28. Basarkar GD, Shirsath GN, Patil SB. Development of microspheres containing diclofenac diethylamine as sustained release topical formulation. Bull Pharm Res 2013;3:14-22.

29. Mohamed MI. Optimization of chlorphenesin emulgel formulation. AAPS J 2004;6:1-7.

30. Murthy TEGK, Kishore VS. Formulation and evaluation of transdermal gels of diltiazem hydrochloride. Indian J Pharm Educ Res 2008;42:272-6.

31. Queiroz MBR, Marcelino NB, Ribeiro MV, Espindola LS, Cunha F, Silva MV. Development of gel with matricaria recutita L. extract for topic application and evaluation of physical-chemical stability and toxicity. Latt Am J Pharm 2009;28:574-9.

32. Singh S, Gajra B, Rawat M, Muthu MS. Enhanced transdermal delivery of ketoprofen from bioadhesive gels. Pak J Pharm Sci 2009;22:193-8.

33. Nandgude T, Thube R, Jaiswal N, Deshmukh P, Chatap V, Hire N. Formulation and evaluation of $\mathrm{pH}$ induced in situ nasal gel of salbutamol sulphate. Int J Pharm Sci Nanotechnol 2008;1:177-83.

34. Moghimipour E, Salimi A, Zadeh BSM. Effect of the various solvents on the in vitro permeability of vitamin B12 through excised rat skin. Trop J Pharm Res 2013;12:671-7.

35. Dhakar RC, Maurya SD, Saluja V. From formulation variables to drug entrapment efficiency of microspheres: a technical review. J Drug Delivery Ther 2012;2:128-33.

36. Biswal I, Dinda A, Mohanty S, Dhara M, Das D, Chowdary KA, et al. Influence of Drug/Polymer ratio on the encapsulation efficiency of highly hydrophilic drug. Asian J Chem 2011;23:1973-8.

37. Sinko PJ. Micrometrics. In: Martin A. editor. Martin's Physical Pharmacy and Pharmaceutical Science. 5th ed. Baltimore: Lippincott Williams and Wilkins; 2006. p. 553-9.

38. Jagtap YM, Bhujbal RK, Ranade AN, Ranpise NS. Effect of various polymers concentrations on physicochemical properties of floating microspheres. Indian J Pharm Sci 2012;74:512-20.

39. Clearly GW. Transdermal controlled release systems. In: Langer RS, Wise DS. eds. Medical applications of controlled release. Vol. 1. Boca Raton, FL: CRC Press; S1984. p. 204-51.

40. Lucero MJ, Vigo J, Leon MJ. A study of shear and compression deformations on hydrophilic gels of tretinoin. Int J Pharm 1994;106:125-33.

41. Harish NM, Prabhu P, Charyulu RN, Gulzar MA, Subrahmanyam EV. Formulation and evaluation of in situ gels containing clotrimazole for oral candidiasis. Indian J Pharm Sci 2009;71:421-7.

42. Martin A. Physical pharmacy, kinetics. First Indian reprint. New Delhi: B. I Waverly; 1994. 